\title{
INTRODUCTION OF A PRACTICAL LESSON FOR THE EVALUATION OF BIOACTIVE QUALITY IN PLANT MATERIALS ADDRESSED TO STUDENTS IN PLANT BREEDING
}

\author{
C. Guijarro-Real, M. Plazas, P. Gramazio, A.M. Adalid-Martínez, J. Prohens, \\ A. Rodríguez-Burruezo, A. Fita \\ Instituto de Conservación y Mejora de la Agrodiversidad Valenciana (COMAV), \\ Universitat Politècnica de València (SPAIN)
}

\begin{abstract}
According to the new market trends, one of the goals in many modern breeding programmes is the development of varieties with enhanced bioactive properties. Despite the importance of evaluating the content of specific molecules, the analysis of the broad antioxidant capacity is often suitable. For instance, if the goal is to evaluate large quantity of materials, or even to compare different agronomical practices to obtain the highest antioxidant properties. Thus, studies related to plant breeding should include subjects related to the knowledge of analytical methods for the evaluation of the bioactive properties in the materials tested. Theoretical lessons establish the basis for understanding the importance of bioactive properties and the influence of stresses in their content. Nevertheless, practical sessions complement this knowledge and improve the competence of future professionals, providing them a tool for the evaluation of bioactive quality in developing breeding materials. We consider therefore that this competence should be acquired during the Master degree in Plant Breeding offered by our institute. Thus, we propose to introduce a practical lesson in the mandatory subject "Instrumental Techniques" aimed to the comparison of two analytical methods for the analysis of bioactive properties. As plant material, we will use water celery, an herbaceous species with great antioxidant properties. The methodology will include the analysis of the antioxidant activity with the DPPH method and the content in total phenolics, both spectrophotometric methods but measuring different aspects of the bioactive quality. The lesson is divided in three sessions of three hours each, in the course of which students will perform all steps for these analyses, including sample preparation, extraction of bioactive molecules, preparation of the calibration curve, and analysis of results. This practical lesson provides students with the competence to evaluate the antioxidant activity of high number of materials using quick and simple spectrophotometric methodologies, and to deal with real problems such as the need of dilution for samples with very high content of bioactive molecules. Moreover, the practical lesson provides the guidelines to adapt the protocols for different materials and consequently to many breeding programmes, and can be also adapted for food technology students.
\end{abstract}

Keywords: Antioxidants, Plant Science studies, specific competence, spectrophotometry, total phenolics.

\section{INTRODUCTION}

Master studies are designed to provide advanced, specialized training of post-graduate students [1]. In Plant Science studies, good knowledge of techniques addressed to analyze nutritional properties of materials is usually needed. In the particular case of Plant Breeding studies, this knowledge can become essential. Traditional breeding has focused mainly on improving the yield of crops [2]. However, nowadays plant breeding programmes also consider other aspects of quality that are of interest for consumers, such as organoleptic and nutritional quality [e.g., 3], together with the introduction of tolerance in crops to pests and illness [2].

Due to the importance of nutritional quality in many breeding programmes, we consider essential that our Plant Breeding master provides students with the competence of analyzing nutritional related traits. It is of particular importance the study of molecules with antioxidant properties. An antioxidant is a molecule able to neutralize other molecules with free radicals, such as reactive oxygen species (ROS). ROS, when are present in excess in the human body, can cause molecular and cellular disorders deriving in several diseases [4]. Within the antioxidants, phenolic compounds deserve special attention. Phenolic compounds include a large number of molecules present in plants as secondary metabolites. From those, flavonoids and phenolic acids, commonly found in fruits and 
vegetables, have demonstrated to possess high antioxidant properties [5]. Thus, increasing the content in phenolic compounds and other antioxidant molecules in fruits and vegetables can derive in a better health state of the consumers.

Despite the interest in evaluating the content in specific molecules, analyses of broad phenolic content and antioxidant capacity are often suitable. Measurements of antioxidant capacity and total content in phenolic molecules can be easily performed by using spectrophotometric methodologies $[6,7]$. These methodologies allow a quick evaluation of a large quantity of materials in a reduced time. Thus, they can be used in breeding programmes aimed to select genotypes that present the highest antioxidant properties. Furthermore, these methodologies can be also used for establishing proper growing conditions that enhance the antioxidant values (e.g., organic vs. conventional), or for selecting specific genotype $x$ environment interactions [8]. However, the application of these methodologies, although broadly described, involves in many cases problems related to the material processing, extraction and analysis validity. Since these situations are not usually explained in the protocols posted, the study of these situations in practical lessons of the related masters is highly desirable.

Our hypothesis is that the introduction of this practical lesson may contribute to an improved learning process for students of the Master degree in Plant Breeding offered by our Institute. Students should be able to put into practice the theoretical knowledge acquired for enhancing learning [9]. Moreover, we consider that practical lessons are good teaching tools for helping in the complete understanding and fixation of the concepts given in the theoretical lessons. In particular, we think that the development of this practical lesson will help students to understand the concept of antioxidant and phenolic molecules, and the difference and correlation between those concepts. In addition, students will obtain the competence of performing real studies focused on the comparison of different antioxidant properties among materials. Finally, encountering with real problems during the practical lesson will teach students how to solve them, thus improving the learning process [10], and also preparing them for their future careers.

\section{THE PRACTICAL SESSION}

The "Evaluation of bioactive quality in plant materials" practical lesson requires nine hours to be completed. Thus, the lesson will consist in three sessions of three hours each, taking place in consecutive days. At the beginning of the lesson, the instructor gives an outline with the steps that are being performed during the lesson, including the protocol of the different analytical methods, to each student (Fig. 1).

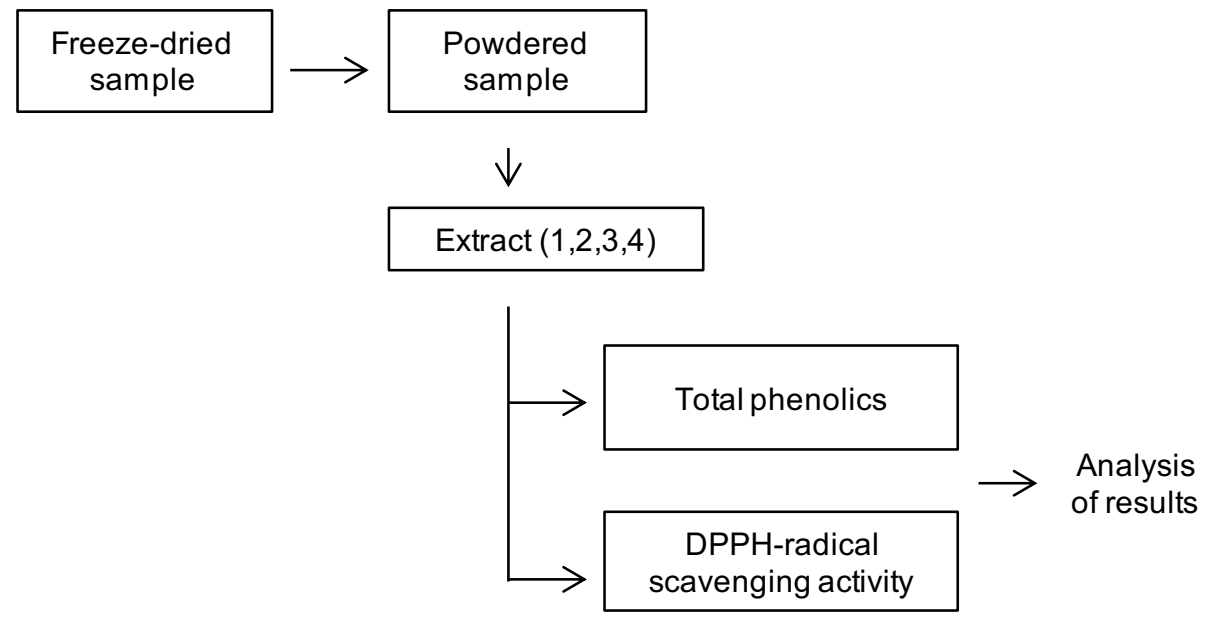

Figure 1. Scheme of the practical lesson.

The first day is aimed to the preparation of solutions and extraction of the antioxidant components. One freeze-dried sample of water celery (Apium nodiflorum (L.) Lag.) is provided to each student. This wild vegetable has been chosen due to the great antioxidant properties that the species presents, together with the high content in phenolic compounds in the leaves [11,12]. Students are first asked to prepare properly the solutions needed for the lesson, considering the volume needed for all the analyses that will be performed in the class, and the different calibration curves that will be used (Table 1). Then, each student follows an extraction protocol according to the instructions of the 
teacher (Table 1), considering that there are four possibilities and each extraction protocol must be repeated by, at least, three students. Students are asked to take notes about the exact quantity of material weighted. At the end of this first session, the solutions are stored in adequate conditions according to the type (it is, room temperature, $4^{\circ} \mathrm{C}$ or $-20^{\circ} \mathrm{C}$ ).

Table 1. Example of the solutions and extraction protocol that students are asked to follow.

\begin{tabular}{|l|l|}
\hline \multicolumn{2}{|c|}{ Solutions needed during the lesson } \\
\hline Extraction solution 1 & Acetone: acetic acid $(70: 0.5 \% \mathrm{v} / \mathrm{v})$ in distilled water \\
\hline Extraction solution 2 & Acetone: methanol $(35: 25 \% \mathrm{v} / \mathrm{v})$ in distilled water \\
\hline Extraction solution 3 & Methanol $70 \%(\mathrm{v} / \mathrm{v})$ in distilled water \\
\hline Extraction solution 4 & Distilled water \\
\hline Diluted Folin-Ciocalteu reagent & $\begin{array}{l}\text { Folin-Ciocalteu reagent } 10 \%(\mathrm{v} / \mathrm{v}) \text { in distilled water, freshly } \\
\text { prepared the day of use }\end{array}$ \\
\hline DPPH reagent & DPPH reagent $0.025 \mathrm{~g} / \mathrm{L}$, freshly prepared the day of use \\
\hline Sodium carbonate solution & Sodium carbonate $60 \mathrm{~g} / \mathrm{L}$ in distilled water \\
\hline \multicolumn{3}{|l|}{ Extraction protocol } \\
\hline 1. & Grind the independent subsample with a pestle. \\
\hline 2. & Weight $0.100 \mathrm{~g}$ of the subsample. \\
\hline 3. & Extract with $5 \mathrm{ml}$ of the extraction solution for $1 \mathrm{hour}$, in continuous stirring. \\
\hline 4. & Centrifuge at 3,500 rpm for 3 min. \\
\hline 5. & Store $1 \mathrm{ml}$ of the supernatant at $-20^{\circ} \mathrm{C}$. \\
\hline
\end{tabular}

The second session is used for analyzing the content in total phenolics of the extract by means of the Folin-Ciocalteu methodology [7]. First, one aliquot of the diluted Folin-Ciocalteu reagent is prepared for all the class (Table 1). Students are then asked to take the extracts and follow the protocol as described in the outline, in triplicate, together with the one calibration curve for all the class (Table 2).

Table 2. Example of the protocols that students are asked to follow.

\begin{tabular}{|l|l|}
\hline \multicolumn{2}{|c|}{ Total phenolics protocol } \\
\hline 1. & Add $500 \mu \mathrm{l}$ of the diluted Folin-Ciocalteu reagent to $65 \mu \mathrm{l}$ of the extract. \\
\hline 2. & Incubate for $5 \mathrm{~min}$ at room temperature and darkness. \\
\hline 3. & Add $500 \mu \mathrm{l}$ of the sodium carbonate solution. \\
\hline 4. & Incubate for $60 \mathrm{~min}$ at room temperature and darkness. \\
\hline 5. & Transfer $200 \mu \mathrm{l}$ to a 96 -well microplate. \\
\hline 6. & Measure the absorbance in a spectrophotometer at $750 \mathrm{~nm}$. \\
\hline 7. & Repeat the measurement each 5 min until the reaction remains stable. \\
\hline 1. & $\quad$ DPPH-radical scavenging activity protocol \\
\hline 2. & Incubate for 10 min at room temperature and darkness. \\
\hline 3. & Transfer $200 \mu$ to a 96 -well microplate. \\
\hline 4. & Measure the absorbance in a spectrophotometer at $515 \mathrm{~nm}$. \\
\hline 5. & Repeat the measurement each 2 min until the loss of absorbance remains stable. \\
\hline
\end{tabular}


One 96-well microplate is used for all the class, in which the reactions corresponding to the extracts and the calibration curve are included (Fig. 2). During the measurements with the spectrophotometer, students are asked to take specific notes about the time and the corresponding absorbance.

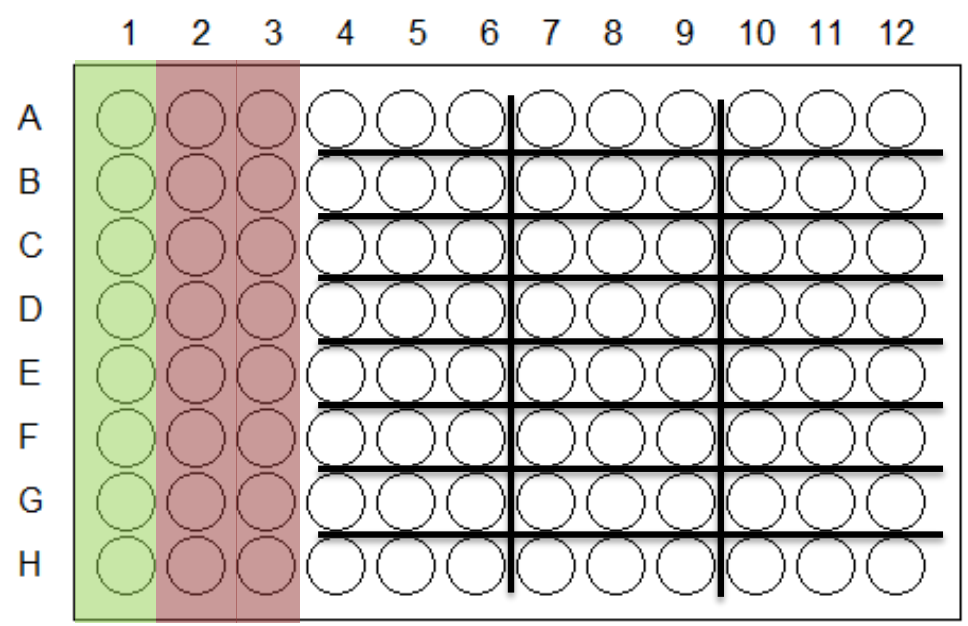

Figure 2. Example of a 96-well microplate filled to read the absorbance. Column 1 is destined to the blank; columns 2 and 3 are destined to the two replications of the calibration curve; and the remaining wells are used for the students, considering that each student fills three consecutive wells with the three replicates performed.

The third session of this practical lesson is used for performing the DPPH-radical scavenging activity protocol [6] and analyzing the results obtained in sessions 2 and 3. First, an aliquot of the DPPH reagent is prepared for all the class (Table 1). Then, students are asked to follow the protocol given in the outline (Table 2), and to fill the 96-well microplate as indicated in Fig. 2. During the measurements, they need to note the loss of absorbance at the corresponding times in which the microplate is read.

The last part of the third session corresponds to the analysis and discussion of results. Each student should be able to give the equation of the calibration curves corresponding to the Folin-Ciocalteu and DPP-radical scavenging activity analyses, and to give a final result for the samples. Then, results are shared with the classmates and discussed. In order to evaluate the knowledge acquired, students are asked to fill a questionnaire (Table 3). The questionnaire includes also some questions addressed to know how students perceive the learning process with this type of practical lessons.

Table 3. Questionnaire filled up by students as evaluation of the practical lesson.

\begin{tabular}{|c|c|c|}
\hline \multicolumn{3}{|c|}{ Results obtained } \\
\hline \multirow{4}{*}{$\begin{array}{l}\text { Content in total phenolics } \\
\text { (average } \pm \text { SE) }\end{array}$} & Extract 1 & \\
\hline & Extract 2 & \\
\hline & Extract 3 & \\
\hline & Extract 4 & \\
\hline \multicolumn{3}{|c|}{$\begin{array}{l}\text { Considering the results, define the extraction solution that you would use for the measurement of total } \\
\text { phenolics by the Folin-Ciocalteu method, and time of incubation before measuring the absorbance }\end{array}$} \\
\hline \multirow{4}{*}{$\begin{array}{l}\text { Content in antioxidant molecules } \\
\text { (average } \pm \mathrm{SE} \text { ) }\end{array}$} & Extract 1 & \\
\hline & Extract 2 & \\
\hline & Extract 3 & \\
\hline & Extract 4 & \\
\hline
\end{tabular}




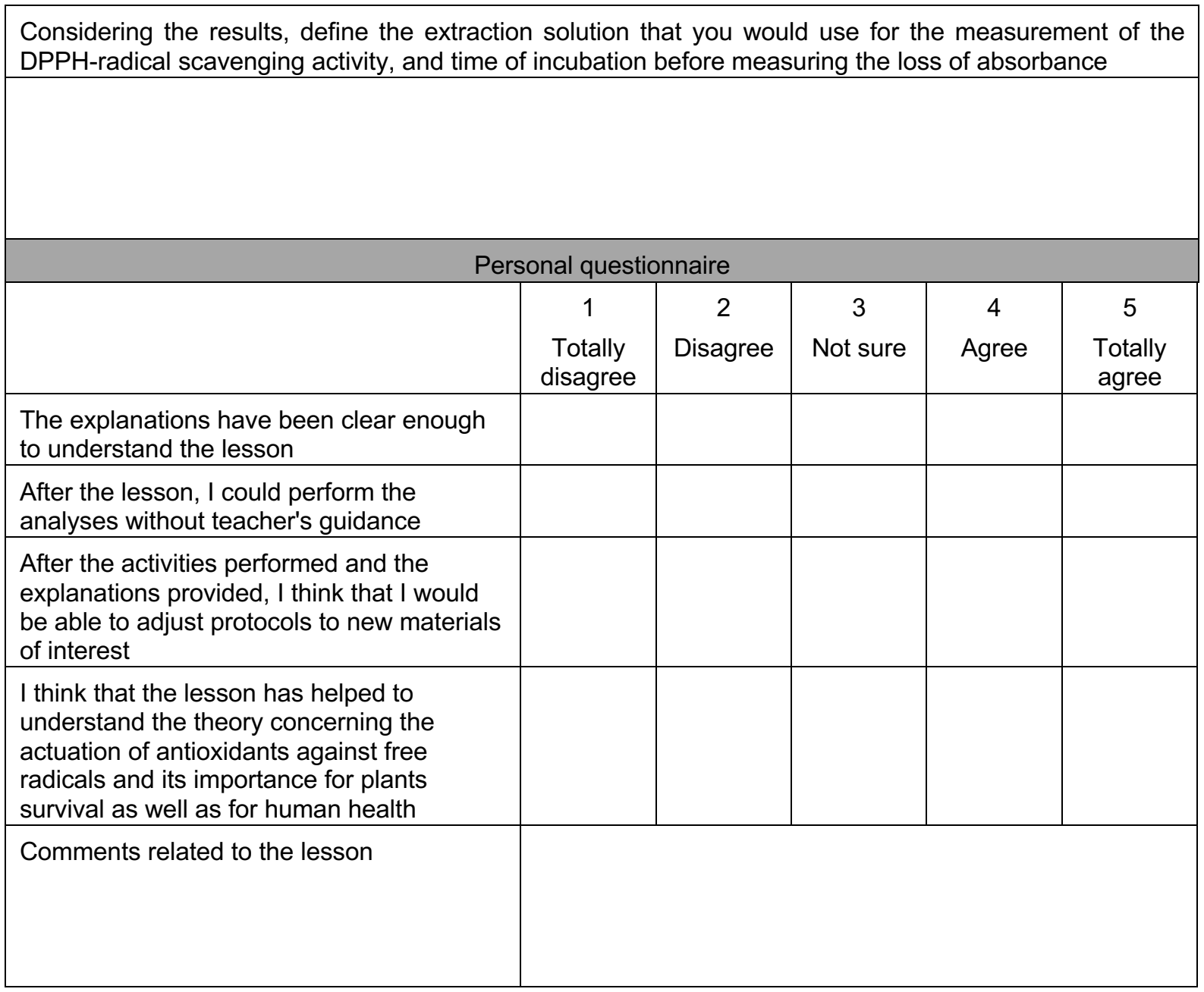

\section{CONCLUSIONS}

The practical lesson should provide students with the competence to evaluate different antioxidant characteristics of plant materials. We consider that this is one way of contributing the development of breeding programmes focused on nutritional traits [13, 14], since the protocols used allow the quick evaluation of a large number of samples. In addition, the lesson is designed to guide students in the adjustments of the protocols, as well as to understand and solve real problems that can occur. In summary, after this practical lesson, students should feel confident in working with the protocols evaluated adapted to different materials. Finally, this practical session could also be applied to other master degrees related to Plant Science, Plant Industry and Food Technology [15, 16].

\section{ACKNOWLEDGEMENTS}

Carla Guijarro-Real is grateful to the Ministerio de Educación, Cultura y Deporte of Spain (MECD) for a predoctoral FPU grant (FPU14-06798). Mariola Plazas is grateful to Generalitat Valenciana and Fondo Social Europeo for a post-doctoral grant (APOSTD/2018/014). Pietro Gramazio is grateful to Universitat Politècnica de València for a post-doctoral contract (PAID-10-18) within the Programa de Ayudas de Investigación y Desarrollo initiative. Ana M Adalid-Martínez is grateful to the Ministerio de Ciencia, Innovación y Universidad of Spain for its support with a post-doctoral contract (PTA201511502-I) within the Subprograma Personal Técnico de Apoyo initiative.

\section{REFERENCES}

[1] A. Ismail, N. Abiddin, A. Hassan. "Improving the development of postgraduates' research and supervision", International Journal of Educational Studies vol. 4, pp. 78-89, 2011. 
[2] M. Gilliham, J. A. Able, S. J. Roy. "Translating knowledge about abiotic stress tolerance to breeding programmes", The Plant Journal vol. 90, pp. 898-917, 2017.

[3] A. Pérez, R. García-Rodríguez, C. Sanz, A. Refoyo. "A10-48-3 and A7-32-10, two strawberry selections with well-balanced nutritional and organoleptic quality", Acta Horticulturae vol. 1156, pp. 363-370, 2017.

[4] S. Prasad, S. C. Gupta, A. K. Tyagi. "Reactive oxygen species (ROS) and cancer: Role of antioxidative nutraceuticals", Cancer Letters vol. 387, pp. 95-105, 2017.

[5] F. Sahidi, P. Ambigaipalan. "Phenolics and polyphenolics in foods, beverages and spices: antioxidant activity and healthy effects - a review", Journal of Functional Foods vol. 18, pp. 820 897, 2015.

[6] M. S. Moura Rufino, R. Elesbao Alves, E. Sousa de Brito, S. Maia de Morais, C. de Goes Samapio, J. Pérez-Jiménez, F. D. Saura-Calixto. Determinação da atividade antioxidante total em frutas pela captura do radical livre ABTS, Fortaleza, Embrapa Agroindústria Tropical, 2007.

[7] V. Singleton, J. Rossi. "Colorimetry of total phenolics with phosphomolybdic phosphotungstic acid reagents", American Journal of Enology and Viticulture vol. 16, pp. 144-158, 1965.

[8] A. M. Ribes-Moya, M. D. Raigón, E. Moreno-Peris, A. Fita, A. Rodríguez-Burruezo. "Response to organic cultivation of heirloom Capsicum peppers: Variation in the level of bioactive compounds and effect of ripening", PLoS One vol. 13, e0207888, 2018. DOI: 10.1371/journal.pone.0207888

[9] J. Wrenn, B. Wrenn. "Enhancing Learning by Integrating Theory and Practice", International Journal of Teaching and Learning in Higher Education vol. 21, pp. 258-265, 2009.

[10] G. R. Norman. "Problem-solving skills, solving problems and problem-based learning", Medical Education vol. 22, pp. 279-286, 1988.

[11] P. Morales, A. M. Carvalho, M. C. Sánchez-Mata, M. Cámara, M. Molina, I. C. F. R. Ferreira. "Tocopherol composition and antioxidant activity of Spanish wild vegetables". Genetic Resources and Crop Evolution vol. 59, pp. 851-863, 2012.

[12] C. Guijarro-Real, J. Prohens, A. Rodríguez-Burruezo, A. M. Adalid-Martínez, M. P. LópezGresa, A. Fita. "Wild edible fool's watercress, a potential crop with high nutraceutical properties", PeerJ in press, 2019.

[13] B. Harakotr, B. Suriharn, M. P. Scott, K. Lertrat. "Genotypic variability in anthocyanins, total phenolics, and antioxidant activity among diverse waxy corn germplasm". Euphytica vol. 203, pp. 237-248, 2015.

[14] V. Kraujalyte, P. R. Venskutonis, A. Pukalskas, L. Česoniene, R. Daubaras. "Antioxidant properties, phenolic composition and potentiometric sensor array evaluation of commercial and new blueberry (Vaccinium corymbosum) and bog blueberry (Vaccinium uliginosum) genotypes", Food Chemistry vol. 188, pp. 583-590, 2015.

[15] S. H. Nile, A. S. Nile, Y. S. Keum. "Total phenolics, antioxidant, antitumor, and enzyme inhibitory activity of Indian medicinal and aromatic plants extracted with different extraction methods". 3 Biotech vol. 7, pp. 1-10, 2017.

[16] I. Juániz, I. Ludwig, E. Huarte, G. Pereira-Caro, J. M. Moreno-Rojas, C. Cid, M. P. de Peña. "Influence of heat treatment on antioxidant capacity and polyphenolic compounds of selected vegetables", Food Chemistry vol. 197, pp. 466-473, 2016. 